\title{
SIMULTANEOUS ADSORPTION OF PHENOL DERIVATIVES FROM WATER ONTO SPHERICAL ACTIVATED CARBON
}

\begin{abstract}
The paper examines single- and multicomponent adsorption onto granular activated carbon. The quantities adsorbed in the study were determined using HPLC with UV detection. The experimental data were analysed using the Langmuir, the Freundlich and the Sips adsorption isotherms. With a single component being adsorbed, high coefficients of determination and low mean square errors indicated that the Sips isotherm fitted the adsorption equilibrium well. Further experiments were carried out using aqueous solutions containing two or three adsorbed components in different proportions. For these solutions, the literature methods of predicting multicomponent equilibrium using single-component data did not yield positive results. Assuming that in the investigated range of concentrations no competitive adsorption occurred, the authors propose a method for calculating the equilibrium concentrations in the liquid phase using the equations obtained for individual components. The results achieved correspond very well to the experimental data.
\end{abstract}

Keywords: phenolic compounds, multicomponent adsorption, adsorption equilibrium

\section{Introduction}

The industrial practice often deals with wastewater containing a multi-component mixture, for example, heavy metal ions [1-4], textile industry contaminants [5, 6], pharmaceutical waste [7, 8], herbicides [9], benzene derivatives [10, 11], hydrocarbons [12, 13] and many others. However, this paper focuses on phenolic compounds.

Phenolic compounds are used industrially as antioxidants, semi-finished products, disinfectants, tannins as well as lubricant and gasoline additives. They are widely utilized in the photographic, petrochemical, dye, pyrotechnic, rubber, plastics, pharmaceutical and agricultural industries. Phenol is used in the production of various chemicals, including drugs, dyes and synthetic resins. It is also a general disinfectant for toilets, stables, cesspools, floors and sewers as well as a solvent for the refining of crude oil. Moreover, it can be found in bactericidal dyes and glues [14-16]. The factories producing and/or using these kinds of chemicals often discharge aqueous waste containing them in large concentrations.

Adsorption is one of the most useful methods for treating such waste streams and preparing drinking water. However, adsorption can be used when the concentration of

\footnotetext{
${ }^{1}$ Faculty of Process and Environmental Engineering, Lodz University of Technology, ul. Wólczańska 213, 90-924 Łódź, Poland, email: wladyslaw.kaminski@p.lodz.pl, elwira.tomczak@p.lodz.pl

${ }^{2}$ Institute of Chemistry, Military University of Technology, ul. gen. S. Kaliskiego 2, 00-908 Warszawa, Poland, email: krzysztof.kusmierek@wat.edu.pl, andrzej.swiatkowski@wat.edu.pl

*Corresponding author: krzysztof.kusmierek@wat.edu.pl
} 
contaminants does not exceed several $\mathrm{mmol} / \mathrm{dm}^{3}$. When the concentration is higher, hybrid methods are utilized first to reduce it to a level suitable for adsorption.

The experimental work and mathematical description of the equilibrium in single- and multicomponent adsorption are the starting point for designing the wastewater treatment process. Since the main purpose of the study was to devise a model suitable for multicomponent adsorption, the following assumptions were made:

1. the adsorbent surface was homogeneous,

2. no interactions occurred between the adsorbed substances,

3. all adsorption sites were equally available to these substances.

Further considerations involved the Langmuir, the Freundlich and the Sips equations for the single components being adsorbed and for the multicomponent systems.

The Langmuir equation for a single adsorbate takes the following form [17]:

$$
q_{e}=\frac{q_{m L} K_{L} C_{e}}{1+K_{L} C_{e}}
$$

where: $q_{e}$ - the adsorbate uptake at equilibrium $[\mathrm{mmol} / \mathrm{g}], C_{e}$ - equilibrium concentration of the adsorbate $\left[\mathrm{mmol} / \mathrm{dm}^{3}\right], q_{m L}$ - the Langmuir monolayer adsorption capacity [ $\mathrm{mmol} / \mathrm{g}$ ], $K_{L}$ - the Langmuir equilibrium adsorption constant $\left[\mathrm{dm}^{3} / \mathrm{mmol}\right]$.

The Langmuir equation for multiple adsorbates can be given as [17]:

$$
q_{e i}=\frac{q_{m L i} K_{L i} C_{e i}}{1+\sum_{j=1}^{N} K_{L j} C_{e j}}
$$

The Freundlich isotherm for a single adsorbate is given by Eq. (3) [18]:

$$
q_{e}=K_{F} C_{e}^{\frac{1}{n_{F}}}
$$

where: $K_{F}$ - the Freundlich constant indicative of the relative adsorption $\left[(\mathrm{mmol} / \mathrm{g})\left(\mathrm{dm}^{3} / \mathrm{mmol}\right)^{1 / n F}\right]$ and $n_{F}$ - dimensionless Freundlich constant.

According to the Ideal Adsorbed Solution Theory (IAST) developed by Myers and Prausnitz [18], for multiple adsorbates the above equation can be written as:

$$
C_{e i}=\frac{q_{e i}}{\sum_{j=1}^{N} q_{e k}}\left(\frac{\sum_{j=1}^{N} n_{F k} q_{e k}}{n_{i} K_{F i}}\right)^{n_{F i}}
$$

The non-modified Sips model for a single adsorbate [19] can be described with Eq. (5):

$$
q_{e}=\frac{q_{m S} K_{S} C_{e}^{n_{S}}}{1+K_{S} C_{e}^{n_{S}}}
$$

where: $q_{m s}$ - the Sips maximum adsorption capacity [mmol/g], $K_{S}$ - the Sips equilibrium constant $\left[\mathrm{dm}^{3} / \mathrm{mmol}\right]$ and $n_{S}$ - the Sips model constant [-].

For multiple adsorbates $[4,20]$ this model takes the form given by Eq. (6):

$$
q_{e i}=\frac{q_{m S i} K_{S i} C_{e i}^{n_{S i}}}{1+\sum_{j=1}^{N} K_{S j} C_{e i}^{n_{S j}}}
$$

The subject literature also provides models of multicomponent adsorption including the interactions between the respective constituents [1, 11-13, 21, 22]. In such cases, certain correction factors are introduced or a more advanced approach is taken involving the 
activity coefficients. In either case, a significant amount of additional lab work is required to determine their values.

\section{Materials and methods}

\section{Materials}

In the experiments the following phenol derivatives were used: $>99 \%$ 4-nitrophenol (4NP), > $99 \%$ 4-methylphenol (4MP) and $99 \%$ 4-chlorophenol (4CP). The chemicals were purchased from Sigma-Aldrich (St. Louis, MO, USA).

The study used type SCN-M spherical activated carbon acquired from the Institute for Sorption and Problems of Endoecology in Kiev [23]. The carbon, made from divinylbenzene-vinylpyridine copolymer, having the form of smooth and hard spherical granules of uniform sizes, has been introduced into commercial production and used for detoxifying blood. The choice of such activated carbon is due to the lack of mineral admixtures (ash) that can partially dissolve in water. Granular commercial activated carbons do not have such advantages. In addition, uniform sizes in which SCN-M occurs cause high repeatability of adsorption experiments.

The porous structure characteristic of the activated carbon was obtained on the basis of low temperature nitrogen adsorption-desorption isotherm (Micromeritics ASAP 2020 volumetric adsorption analyzer, Norcross, USA). The specific surface area $\left(S_{\mathrm{BET}}\right)$ was calculated by the BET method, while the micropore and mesopore volumes were calculated using $t$-plot and Barrett-Joyner-Halenda models. The elemental analysis to determine carbon, hydrogen, nitrogen and sulfur contents in the adsorbent was performed on a Vario MICRO Cube analyzer (Elementar Analysensysteme GmbH, Langenselbold, Germany).

\section{Adsorption procedure}

In order to determine the adsorption isotherms, $0.02 \mathrm{~g}$ of spherical activated carbon and $0.030 \mathrm{dm}^{3}$ of the solution containing a known concentration of $4 \mathrm{NP}$ and/or $4 \mathrm{MP}$ and/or $4 \mathrm{CP}$ were placed in an Erlenmeyer flask and shaken for $8 \mathrm{~h}$ at $25{ }^{\circ} \mathrm{C}$. After mixing, the liquid phase was passed through a $0.2 \mu \mathrm{m}$ pore size filter and analyzed chromatographically. The adsorption was performed using single, binary and ternary solutions with water as the solvent. The concentrations of the solutes were selected according to the Gibbs triangle shown in Figure 1. Points A, B and C are single component solutions. For single component solution initial concentration was change from 0.3 to 1.8 every $0.3 \mathrm{mmol} / \mathrm{dm}^{3}$. Point on sides D, E, F, G, and I, H are binary component solutions. Points J, K, and L are ternary solutions. Total concentration of components for points on the Gibbs triangle sides and inside was kept at $0.9 \mathrm{mmol} / \mathrm{dm}^{3}$.

The adsorbate uptake at equilibrium, $q_{e i}[\mathrm{mmol} / \mathrm{g}]$, was calculated from the equation:

$$
q_{e i}=V \frac{C_{0 i}-C_{e i}}{m_{S}}
$$

where: $C_{0 i}$ - initial concentration of the $i$-th component $\left[\mathrm{mmol} / \mathrm{dm}^{3}\right], C_{e i}-$ equilibrium concentration of the $i$-th component in the liquid phase $\left[\mathrm{mmol} / \mathrm{dm}^{3}\right], V$ - volume of the solution $\left[\mathrm{dm}^{3}\right], m_{S}-$ mass of the activated carbon $[\mathrm{g}]$. 


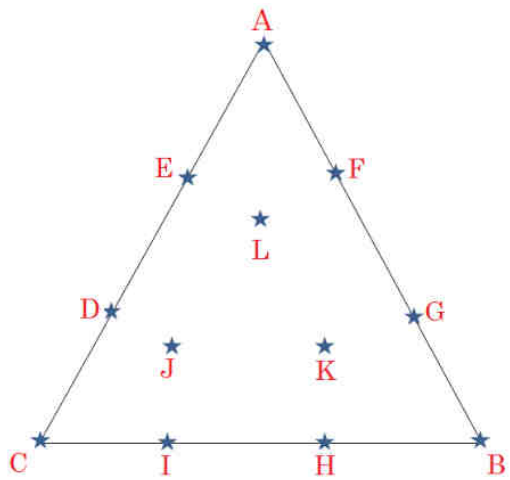

Fig. 1. Experimental points location at Gibbs triangle

\section{Analytical method}

The concentration of the adsorbates was determined using HPLC with ultraviolet detection (Shimadzu LC-20, Kioto, Japan). Chromatographic measurement was performed using an Phenomenex Luna C18, $4.6 \times 150 \mathrm{~mm}, 3 \mathrm{~mm}$ column (Torrance, USA). For separation of the phenols, gradient elution of two solvents was used: $0-5$ min $20 \%$ Solvent A, 5-10 $\min 20-30 \%$ Solvent A, 10-20 min 30\% Solvent A, where Solvent A was acetonitrile and Solvent B was water adjusted to $\mathrm{pH} 3.0$ with acetic acid (remaining percentage). The flow rate was set at $0.25 \mathrm{~cm}^{3} / \mathrm{min}$ and the effluent was monitored using a diode-array detector at the wavelengths of 278,274 and $308 \mathrm{~nm}$, which correspond to the maximum absorption peaks of the $4 \mathrm{CP}, 4 \mathrm{MP}$ and $4 \mathrm{NP}$, respectively. Calibration curves were constructed by plotting integrated peak heights versus phenols concentrations. Linearity was obtained in the studied ranges from 0.01 to $0.5 \mathrm{mmol} / \mathrm{dm}^{3}$ with correlation coefficients $\left(R^{2}\right)$ better than 0.998 . The equations for the regression line $(n=3)$ for $4 \mathrm{CP}$, 4MP and 4NP were: $y=178.5 x-0.818 ; y=249.3 x-0.147$ and $y=1357.0 x-8.915$, respectively.

\section{Results and discussion}

\section{Adsorbent properties}

Nitrogen adsorption-desorption isotherm for the activated carbon determined at $77.4 \mathrm{~K}$ is shown in Figure 2. The specific surface area of the carbon $\left(S_{\mathrm{BET}}\right)$ was $1290 \mathrm{~m}^{2} / \mathrm{g}$. The micropore $\left(V_{m i}\right)$ and mesopore $\left(V_{m e}\right)$ volumes calculated from the adsorption isotherm were found to be 0.595 and $0.265 \mathrm{~cm}^{3} / \mathrm{g}$, respectively. The activated carbon sample was subjected to elemental analysis and observed to contain C: $94.26 \%, \mathrm{~N}: 2.07 \%, \mathrm{H}: 1.22 \%$. S: $0.27 \%$, (w/w) and $\mathrm{O}$ as the rest up to $100 \%$, so the SCN-M is activated carbon with a high content of element $\mathrm{C}$. This indicates that SCN-M is cleaner than typical granular commercial activated carbons. 


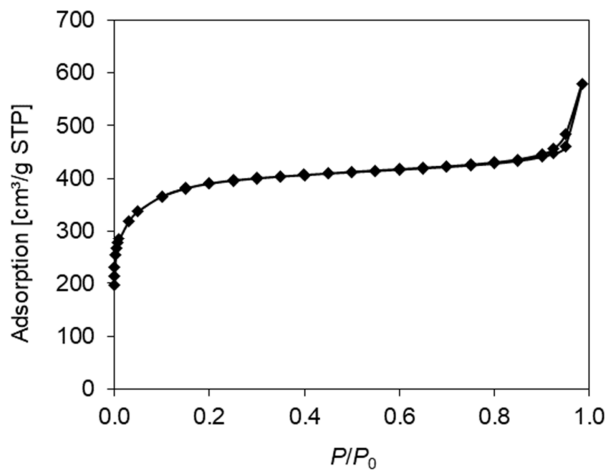

Fig. 2. Nitrogen adsorption-desorption isotherm of the activated carbon at $77.4 \mathrm{~K}$ (where STP means standard temperature and $P$ pressure)

\section{Adsorption equilibrium in single component solutions}

The subject literature proposes numerous ways of modelling the adsorption of single substances $[19,24,25]$. They usually rely on equations with two or three parameters. For further analysis, however, the Langmuir (1), the Freundlich (3) and the Sips (5) isotherms were chosen because they provide simple multi-adsorbate models based on equations determined for single substances. Table 1 summarizes the parameters of the isotherms calculated for single components, the coefficient of determination $R^{2}$ and the root mean square error $\delta$ of the approximation.

Table 1

Parameters of the isotherms and accuracy of the approximation performed with the Langmuir, the Freundlich and the Sips equations

\begin{tabular}{|l|c|c|c|c|c|c|}
\hline Adsorbate & \multicolumn{2}{|c|}{ Langmuir } & \multicolumn{2}{c|}{ Freundlich } & \multicolumn{2}{c|}{ Sips } \\
\hline \multirow{4}{*}{$4 \mathrm{NP}$} & $q_{m L}$ & 2.166 & $K_{F}$ & 3.209 & $q_{m s}$ & 3.276 \\
\cline { 2 - 7 } & $K_{L}$ & 96.29 & $n_{F}$ & 0.249 & $K_{S}$ & 3.963 \\
\cline { 2 - 7 } & $R^{2}$ & 0.941 & $R^{2}$ & 0.979 & $n_{S}$ & 0.466 \\
\cline { 2 - 7 } & $\delta$ & 0.154 & $\delta$ & 0.092 & $R^{2}$ & 0.995 \\
\cline { 2 - 7 } & & & & & $\delta$ & 0.044 \\
\hline \multirow{4}{*}{$4 \mathrm{MP}$} & $q_{m L}$ & 2.083 & $K_{F}$ & 2.556 & $q_{m s}$ & 3.440 \\
\cline { 2 - 7 } & $K_{L}$ & 30.05 & $n_{F}$ & 0.260 & $K_{S}$ & 2.039 \\
\cline { 2 - 7 } & $R^{2}$ & 0.924 & $R^{2}$ & 0.971 & $n_{S}$ & 0.441 \\
\cline { 2 - 7 } & $\delta$ & 0.152 & $\delta$ & 0.093 & $R^{2}$ & 0.984 \\
\hline \multirow{4}{*}{$4 \mathrm{CP}$} & $q_{m L}$ & 2.144 & $K_{F}$ & 3.120 & $q_{m s}$ & 4.308 \\
\cline { 2 - 7 } & $K_{L}$ & 62.88 & $n_{F}$ & 0.270 & $K_{S}$ & 1.715 \\
\cline { 2 - 7 } & $R^{2}$ & 0.921 & $R^{2}$ & 0.989 & $n_{S}$ & 0.409 \\
\cline { 2 - 7 } & $\delta$ & 0.173 & $\delta$ & 0.064 & $R^{2}$ & 0.996 \\
\cline { 2 - 7 } & & & & & $\delta$ & 0.039 \\
\hline
\end{tabular}

Figure 3 compares the experimental results obtained for a single component, i.e. 4NP, $4 \mathrm{MP}$ and $4 \mathrm{CP}$ respectively, to the equilibrium predicted with the selected equations.

Considering the differences between the experimental and calculated results it should be noted that the Sips model, combining the Langmuir and the Freundlich isotherms, provided the most accurate approximation. It should also be mentioned that the Freundlich 
equation itself is a two parameter model and gives not much worse an approximation of the adsorption equilibrium than the Sips model.

a)

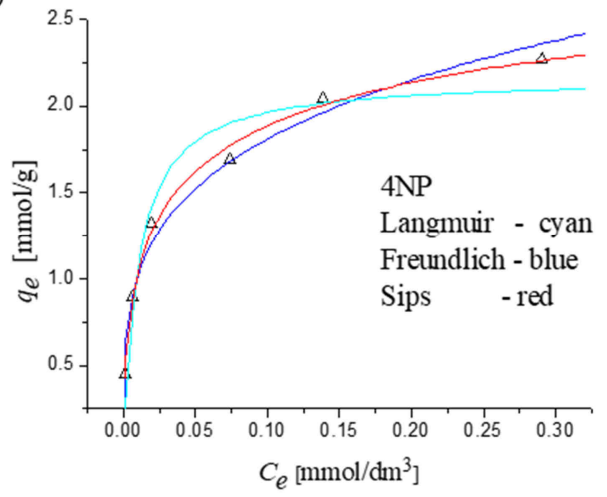

b)

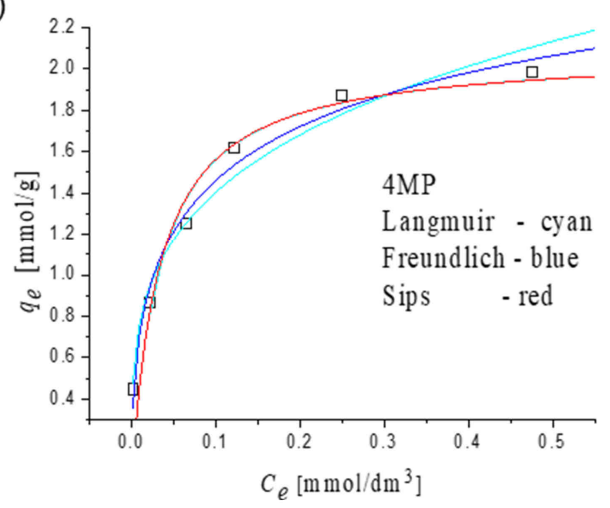

c)

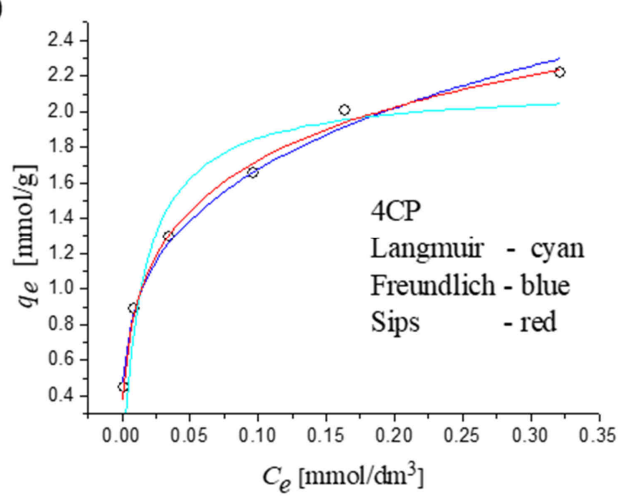

Fig. 3. Comparison of the experimental and calculated results obtained for: a) $4 \mathrm{NP}$, b) $4 \mathrm{MP}$, c) $4 \mathrm{CP}$ 


\section{Multicomponent adsorption isotherms - literature approach}

In the first place, the equations given in the literature were tested with regard to the multicomponent systems. For this purpose, Eqs. (2), (4) and (6) were selected because they describe multicomponent adsorption in accordance with the Langmuir, the Freundlich and the Sips equations using single component adsorption equations.

The comparisons of the experimental and calculated results are shown in Figures 4-7.

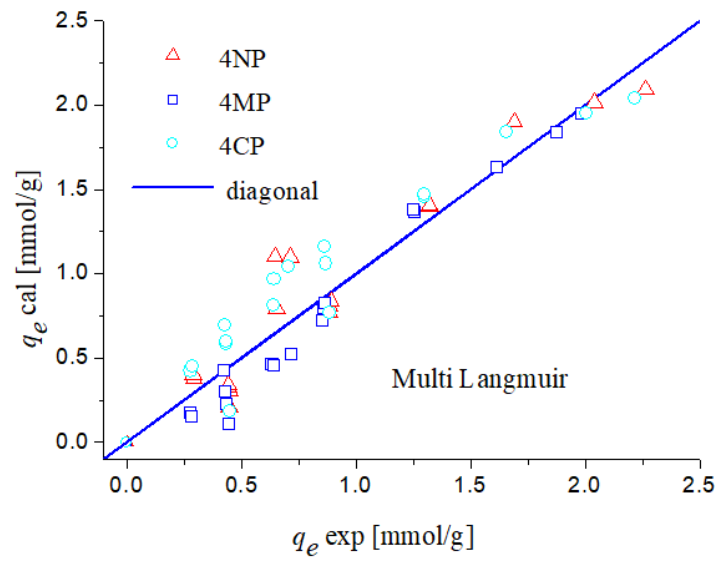

Fig. 4. Adsorbate uptake: experimental and calculated with the multi-Langmuir isotherm (2)

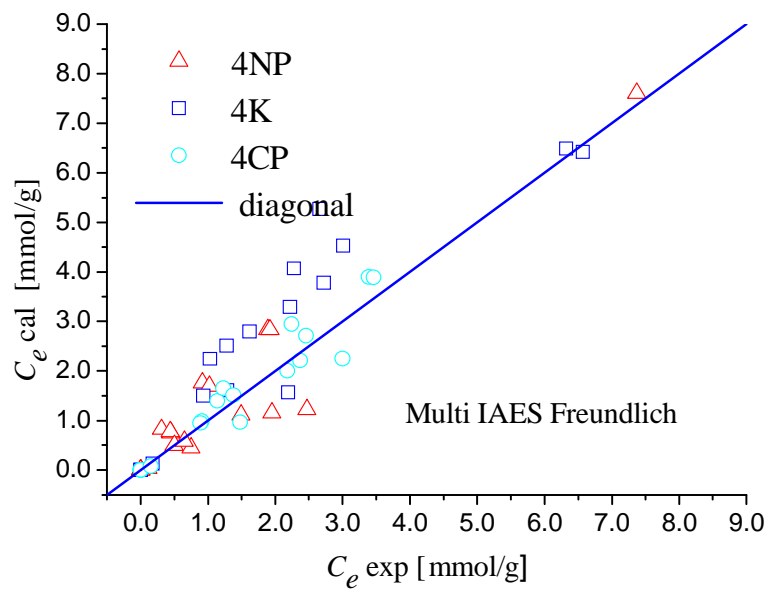

Fig. 5. Equilibrium concentration in the liquid phase: experimental and calculated with the multi-IAES-Freundlich isotherm (4) 


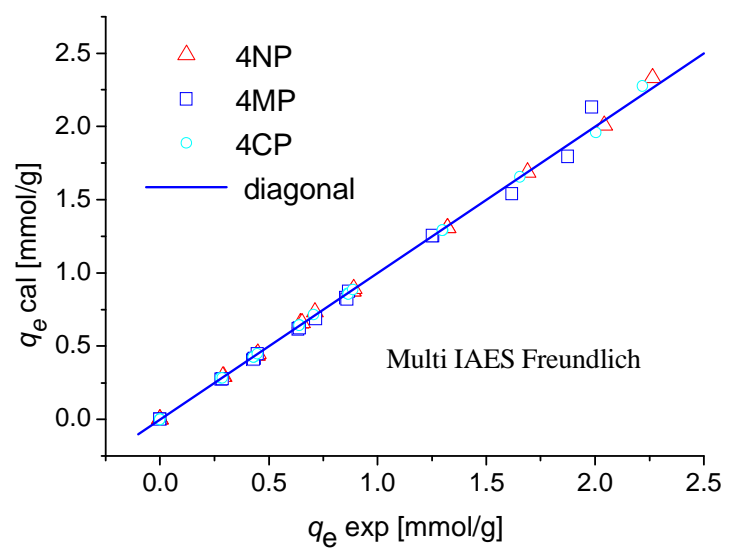

Fig. 6. Adsorbate uptake: experimental and calculated with the multi-IAES-Freundlich isotherm

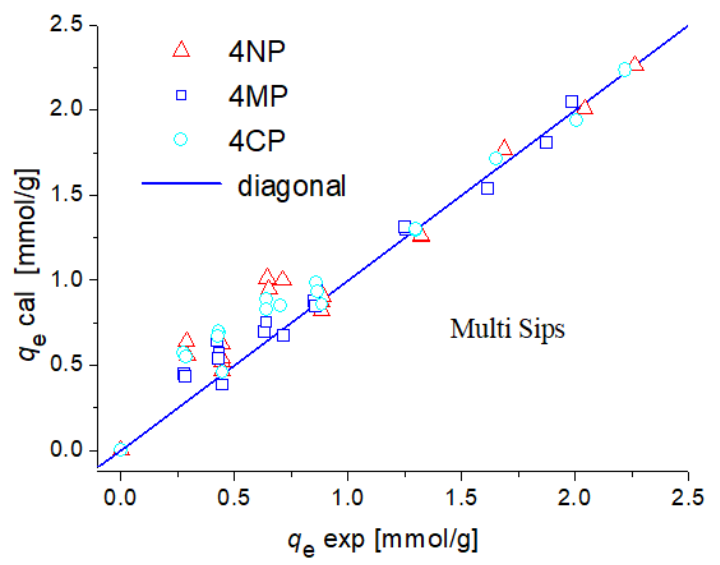

Fig. 7. Adsorbate uptake: experimental and calculated with the multi-Sips isotherm (6)

For the equilibrium concentration $C_{e}$ calculated with the multi-IAES-Freundlich equation, the concentration in the adsorbent $q_{e}$ was determined using Eq. (7). The results are presented in Figure 6.

The following are the main faults of the selected methods:

1. The accuracy of the calculations is unsatisfactory when using the multi-Langmuir and the Sips equations.

2. For a single adsorbed component, the Sips equation approximates the adsorption equilibrium better compared with the Freundlich equation. However, the multi-IAES approach based on the Freundlich isotherm provides a much better approximation of the equilibrium in multicomponent systems.

3. When describing multicomponent adsorption, the same formula for each single component is needed. 
4. The use of more advanced methods e.g. the real adsorbed solution theory (RAST), the heterogeneous ideal adsorbed solution theory (HIAST) requires defining interactions and significant additional amount of experimental work.

\section{Isotherms for multiple adsorbates - the authors' approach}

In order to approximate the adsorption equilibrium in multicomponent systems additional assumptions were made:

1. In the selected range of concentrations no competitive adsorption occurred.

2. The adsorption of each component from a multicomponent solution followed the equation for a single component.

3. The initial concentration of each component in a multicomponent solution was known.

According to the above, the single component equation was fulfilled for each of the adsorbed components. On the other hand, the resulting equilibrium concentration of each component was unknown. Therefore, at thermodynamic equilibrium the quantity of each component calculated from its initial concentration and the volume of the solution was equal to the quantity adsorbed on the activated carbon plus the quantity that was left in the liquid phase. The mass balance for the respective components can be written in the form of Eqs. (8), (9) and (10). They are transformed forms of Eq. (7):

$$
\begin{gathered}
C_{04 N P}-\frac{m_{S} q_{e 4 N P}\left(C_{e 4 N P}\right)}{V}-C_{e 4 N P}=0 \\
C_{04 M P}-\frac{m_{S} q_{e 4 M P}\left(C_{e 4 M P}\right)}{V}-C_{e 4 M P}=0 \\
C_{04 C P}-\frac{m_{S} q_{e 4 C P}\left(C_{e 4 C P}\right)}{V}-C_{e 4 C P}=0
\end{gathered}
$$

Equations (8), (9) and (10) allow $q_{e}$ to be calculated using solely experimental data, i.e. the initial concentration $\left(C_{0}\right)$, the equilibrium concentration $\left(C_{e}\right)$, the mass of the adsorbent $\left(m_{S}\right)$ and the volume of the solution $(V)$.

On the other hand in Eqs. (8), (9) and (10) the equilibrium concentrations $\left(q_{e}\right)$ of $4 \mathrm{NP}$, $4 \mathrm{MP}$ and $4 \mathrm{CP}$ in the sorbent were calculated from the corresponding Sips equations (5) including the parameters given in Table 1 .

In order to simultaneously fulfil Eqs. (8), (9) and (10) the following approach was adopted.

First, find arguments for which the function given by Eq. (11) reached the minimum:

$$
\begin{gathered}
\min F\left(C_{e 4 N P}, C_{e 4 M P}, C_{e 4 C P}\right)=\left(C_{04 N P}-\frac{m_{S} q_{e 4 N P}\left(C_{e 4 N P}\right)}{V}-C_{e N P}\right)^{2}+ \\
\left(C_{04 M P}-\frac{m_{S} q_{e 4 M P}\left(C_{e 4 M P}\right)}{V}-C_{e M P}\right)^{2}+\left(C_{04 C P}-\frac{m_{S} q_{e 4 C P}\left(C_{e 4 C P}\right)}{V}-C_{e C P}\right)^{2}
\end{gathered}
$$

with the constraints $C_{e 4 N P} \in\left\langle 0, C_{04 N P}\right\rangle, C_{e 4 M P} \in\left\langle 0, C_{04 M P}\right\rangle, C_{e 4 C P} \in\left\langle 0, C_{04 C P}\right\rangle$

where $q_{e 4 N P}\left(c_{e 4 N P}\right), q_{e 4 M P}\left(c_{e 4 M P}\right), q_{e 4 C P}\left(c_{e 4 C P}\right)$ are single component equations, which may differ in formula. 
If any of the components were not present in the solution, their initial concentration was assumed to be zero. When the mass balance was fulfilled for all the components, the objective function given by Eq. (11) reached a minimum of zero.

To solve Eq. (11) the MATLAB fmincon procedure was used to search for the minimum of the objective function with one, two or three variables.

The calculated equilibrium concentrations $\left(C_{e}\right.$ and $\left.q_{e}\right)$ were in very good agreement with those obtained using strictly experimental data.

The errors in $C_{e}$ calculated numerically resulted not only from the errors in measuring $C_{0}$, but also from the Sips equation employed to approximate the experimental data and the errors in determining the extremum of the objective function.

Figure 8 compares the experimental results with those calculated for the compositions depicted in the Gibbs triangle. The root mean square error between the experimental $\left(q_{e}\right.$ exp $)$ and calculated $\left(q_{e}\right.$ cal $)$ values was $0.0155,0.0199$ and 0.0230 for $4 \mathrm{NP}, 4 \mathrm{MP}$ and $4 \mathrm{CP}$, respectively.

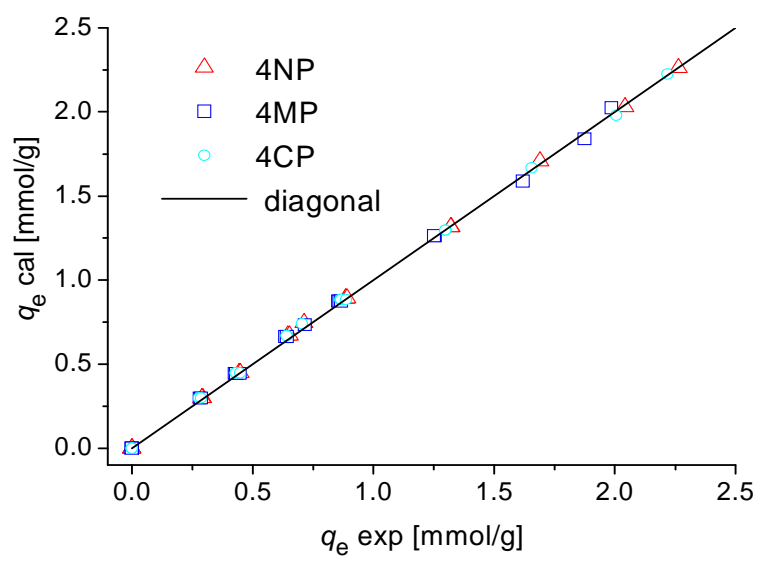

Fig. 8. Comparison of the experimental and calculated results for the adsorbates - proposed approach

\section{Conclusion}

- The authors propose a method for describing the adsorption equilibrium in binary and ternary solutions with water as the solvent, based on the equations obtained for single-component adsorption from aqueous solutions.

- The proposed method can also be applied to solutions containing more than three adsorbed components.

- Based on the initial concentration of the adsorbed component and the single-component adsorption model it is possible to calculate the equilibrium concentration of each component in a multicomponent system.

- When describing multicomponent adsorption, each component may have a different formula for sorption isotherm. 


\section{References}

[1] Zhang L, Wei J, Zhao X, Li F, Jiang F, Zhang M, et al. Chem Eng J. 2016;285:679-89. DOI: 10.1016/j.cej.2015.10.013.

[2] Senthilkumar G, Murugappan A. Inter J Eng Res Technol. 2015;4(8):58-66. www.ijert.org.

[3] Tomczak E, Kamiński W. Ecol Chem Eng S. 2012;19(2):227-37. DOI: 10.2478/v10216-011-0017-8.

[4] Reynel HE, Mendoza-Castillo DI, Hernández-Montoya V, Bonilla-Petriciolet A. Multicomponent removal of heavy metals from aqueous solution using low-cost sorbents. In: Antizar-Ladislao B, Sheikholeslami R, editors. Water Production and Wastewaters Treatment. New York: Nova Science Publisher; 2011. ISBN: 9781617285035.

[5] Parvaresha V, Hashemib H, Khodabakhshic A, Sedehid M. Desalin Water Treat. 2018;111:345-50. DOI: 10.5004/dwt.2018.22204.

[6] Holkar CR, Jadhav AJ, Pinjari DV, Mahamuni NM, Pandit AB. J Environ Manage. 2016;182:351-66. DOI: 10.1016/j.jenvman.2016.07.090.

[7] Renita AA, Kumar PS, Srinivas S, Priyadharshini S, Karthika M. Desalin Water Treat. 2017;87:160-78. DOI: 10.5004/dwt.2017.21311.

[8] Kårelid V, Larsson G, Björlenius B. J Environ Manage. 2017;193:163-71. DOI: 10.1016/j.jenvman.2017.01.078.

[9] Kaminski W, Kusmierek K, Swiatkowski A. Adsorption. 2014;20(7):899-904. DOI: 10.1007/s10450-014-9633-9.

[10] Jadhav AJ, Srivastava VC. Chem Eng J. 2013;229:450-9. DOI: 10.1016/j.cej.2013.06.021.

[11] Mohamed EF, Andriantsiferana C, Wilhelm AM, Delmas H. Environ Technol. 2011;32(12):1325-36. DOI: $10.1080 / 09593330.2010 .536783$.

[12] Erto A, Lancia A, Musmarra D. Sep Purif Technol. 2011;80:140-7. DOI: 10.1016/j.seppur.2011.04.021.

[13] Erto A, Lancia A, Musmarra D. Microporous Mesoporous Mat. 2012;154:45-50. DOI: 10.1016/j.micromeso.2011.10.041.

[14] Atieh MA. APCBEE Proc. 2014;10:136-41. DOI: 10.1016/j.apcbee.2014.10.031.

[15] Peñalver A, Pocurull E, Borrull F, Marcé RM. J Chromatogr A. 2002;953(1-2):79-87. DOI: 10.1016/S0021-9673(02)00113-9.

[16] Puig D, Barcelo D. Trends Analyt Chem. 1996;15(8):362-75. DOI: 10.1016/0165-9936(96)00057-X.

[17] Abdehagh N, Tezel FH, Thibault J. Adsorption. 2016;22:357-70. DOI: 10.1007/s10450-016-9784-y.

[18] Neris JB, Luzardo FHM, da Silva EGP, Velasco FG. Chem Eng J. 2019;357:404-20. DOI: 10.1016/j.cej.2018.09.125.

[19] Foo KY, Hameed BH. Chem Eng J. 2010;156:2-10. DOI: 10.1016/j.cej.2009.09.013.

[20] Luo Z, Zhang Z, Zhou P, Liu Y, Ma G, Lei Z. J Ind Eng Chem. 2015;27:164-74. DOI: 10.1016/j.jiec.2014.12.031.

[21] Porter JF, McKay G, Choy KH. Chem Eng Sci. 1999;54:5863-85. DOI: 10.1016/S0009-2509(99)00178-5.

[22] Dutcher CS, Ge X, Wexler AS, Clegg SL. J Phys Chem A. 2013;117(15):3198-213. DOI: 10.1021/jp310860p.

[23] Lahaye J, Nanse G, Bagreev A, Strelko V. Carbon. 1999;37(4):585-90. DOI: 10.1016/S0008-6223(98)00225-5.

[24] Deihimi N, Irannajad M, Rezai B. J Environ Manage. 2018;227:277-85. DOI: 10.1016/j.jenvman.2018.08.089.

[25] Derakhshani E, Naghizadeh A, Khodadadi M. Health Scope. 2017;6(2):e40416. DOI: $10.5812 /$ jhealthscope.40416. 